\title{
UTILIZING QUALITATIVE RESEARCH IN RELIGIOUS-BASED CHARITY GOVERNANCE: EXPERIENCE AND VALUE LESSON
}

\author{
Nur Farahiah Azmi ${ }^{1}$, Hazriah Hasan ${ }^{2 *}$, Mohd Nor Hakimin Bin Yusoff ${ }^{3}$, Siti Rohana Mohamad ${ }^{4}$
}

1 Faculty of Entrepreneurship and Business, Universiti Malaysia Kelantan, Malaysia

Email: nurfarahiah@umk.edu.my

2 Faculty of Entrepreneurship and Business, Universiti Malaysia Kelantan, Malaysia

Email: hazriah.h@umk.edu.my

3 Faculty of Entrepreneurship and Business, Universiti Malaysia Kelantan, Malaysia

Email: hakimin@umk.edu.my

$4 \quad$ Faculty of Entrepreneurship and Business, Universiti Malaysia Kelantan, Malaysia

Email: rohana@umk.edu.my

* Corresponding Author

\section{Article Info:}

Article history:

Received date:.22.01.2020

Revised date: 09.02 .2020

Accepted date: 20.02.2020

Published date: 15.03.2020

To cite this document:

Azmi, N. F., Hasan, H., Yusoff, M. N. H., \& Mohamad, S. R. (2020). Utilizing Qualitative Research in Religious-Based Charity Governance: Experience and Value Lesson. International Journal of Modern Trends in Social Sciences, 3 (11), 9298.

DOI: $10.35631 / \mathrm{IJMTSS} .311007$.

\begin{abstract}
:
Qualitative research is highly acknowledged for their valuable contribution to various research disciplines, including governance. Therefore, this paper aimed to report real-life researcher experience in conducting an interview with Islamic charity. Findings from this study revealed four main challenges faced by the researchers, such as participant recruitment, language barrier, confidentiality, and time and venue for the interview. Such outcomes offered valuable insight for future researchers regarding possible challenges and their subsequent solutions in conducting interviews in the context of Islamic charity governance research.
\end{abstract}

Keywords:

Islamic Charity; Governance; Religious Based Charity, Qualitative Research

\section{Introduction}

A series of governance scandals and issues have surfaced from not-for-profit (NFP) organizations over the past years, such as mismanagement or ineffective management, misused 
public funds, and various irregularities. Their emergence has shaken public confidence worldwide due to them being evidence of bad governance practice. As a result, this has led to an increase in governance research.

Therefore, various government initiatives have been developed in certain countries, which include the establishment of governance codes to aid these NFP organizations and their members. For instance, the Australian Charities and Not-for-Profits Commission (ACNC) acts as a regulatory body in Australia tasked with overseeing the governance practices of registered charities and NFP organizations. It has underlined five governance standards to be adhered by their charities and NFP organizations to allow their registration under its guidance. Meanwhile, the Singaporean government has developed the Charity Council to promote and encourage the adoption of good governance and the best practices by affiliated charities and NFP organizations (Chokkalingam \& Ramachandran, 2015). However, pressing issues have continued to burden NFP organizations with the emerging spotlight towards current research and their massive contributions in terms of economy, social, religious, and spiritual aspects (Azmi, Hasan, \& Yusoff, 2018). One of the sub-groups, which is commonly known as Islamic NFP organizations has been hounded by governance scandals and issues. In an attempt to ensure proper management for Islamic charities, excellent governance practice is a particularly vital mechanism to correct any managerial issues and scandals found in these organizations. Good governance practices have been linked with positive results in facilitating such organizations towards facing pertinent challenges and delivering their organizational social objectives (Arshad, Razak, \& Bakar, 2014). Hence, this paper was drawn using data obtained from a qualitative evaluation of governance practices upheld by the Islamic charities of Australia conducted in 2016. Despite the study having had included all documentary data obtained, this particular paper solely focused on challenges encountered during the interview sessions.

\section{Literature Review}

\section{The Importance of Adopting A Qualitative Research Method in Governance Research}

Governance research can be undertaken using quantitative, qualitative, or mixed research methods. Morse and Richards (2002) have shown the methodological purposiveness of a study, which subsequently led to the selected research approach for attaining rich and complete findings. As stated by Kyngas (2020), the adoption of qualitative method is suitable if the study is complex or little is known on the study. It is because, the research able to understand the participants' worldview through intensely listening to and respecting their own voice and their own interpretation of life events (Ponterotto, 2010).

Nonetheless, discourses on the strength of qualitative research are widely pronounced in various research studies. According to Miles and Huberman (1994a), qualitative data has notably strong potential to deliver "thick descriptions" and "strong impact" for the issues being studied. Such a notion is attributable to qualitative research concerns having shown to reflect an in-depth understanding of human beings. Meanwhile, Baxter and Jack (2008) have underlined the method's capacity to provide opportunities in exploring the multiple facets of the issue, which is studied via various data sources. It incorporates the utilization and collection of a multitude of empirical materials in order to yield a better understanding of the subject matter (Denzin \& Lincoln 2000). Similarly, Doz's (2011) opinion has highlighted qualitative research and its role in opening the "envelope of known" by battling the difficulties one encounters when collecting empirical evidence. 
In line with this notion, several descriptions of qualitative research can be noted. Creswell (2014) refers to it as obtaining information on man or society that is related to social or human issues. Merriam (2009) has further described it to involve "how people interpret their experiences", "how they construct their worlds", and "what meaning they attribute to their experiences". As qualitative research serves to complement a rich, detailed and reliable context, its selection as the research method will thus unleash much insight regarding governance practice in Islamic NFP organizations. According to McNulty, Zattoni, and Douglas (2013), its adoption in governance research enables a researcher to tap into rich and extensive knowledge regarding the phenomenon being studied. The method allows one to address the research gap observed in governance research, especially in the context of Islamic charities.

\section{The Challenges of Adopting A Qualitative Research}

Due to the importance of qualitative data itself, a researcher has to be incredibly careful and conversant with the process of data collection. Patton (2002) has stated that qualitative research calls for the researcher to have adequate experience in conducting fieldwork. Furthermore, they must be able to respond and adapt immediately to the studied subject due to their status as the primary instrument for data collection and analysis (Merriam, 2009). Such necessity is brought upon the method's relevance and concern for the studied phenomenon and its interaction with the associated social actors.

Moreover, Denzin and Lincoln (2000) have stressed on the significance of personal characteristics possessed by a qualitative researcher throughout an interview process. Therefore, they should fastidiously prepare themselves as they are responsible for capturing the participant's story. According to Holloway and Biley (2011), the qualitative researcher must be able to capture the emotion of the participants and reflect it in the findings of the study. This is a challenging task to be tasked with, but sufficient preparation and knowledge are the keys to becoming a good qualitative researcher.

\section{Method}

This section explicated the step-by-step procedures carried out by the researchers in this study.

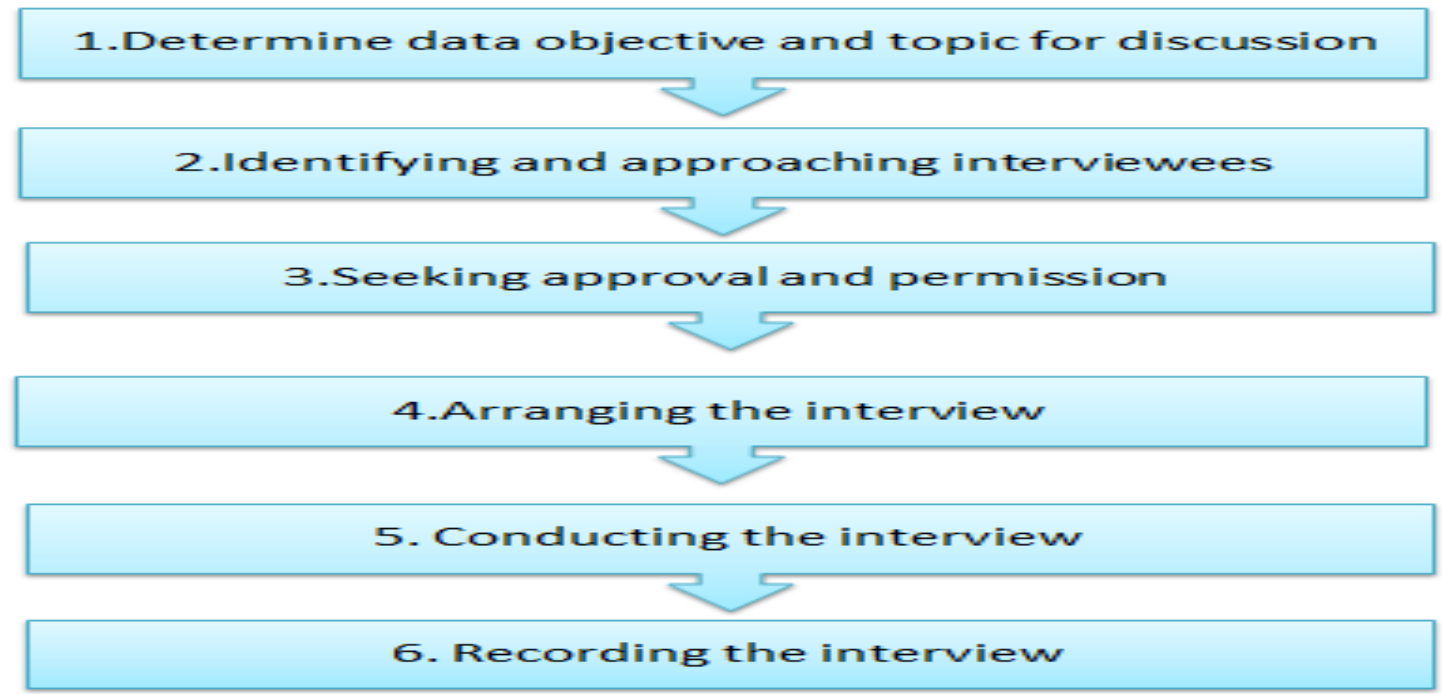

Figure 1: Steps for Conducting the Interview

Source: Adopted from Crowther and Lancaster (2012)

Copyright $\odot$ GLOBAL ACADEMIC EXCELLENCE (M) SDN BHD - All rights reserved 


\section{Determining Data Objective and Topic for Discussion}

The first step in conducting the interview was establishing the objective and topic for discussion. Therefore, the researchers conducted the interviews based on the research questions designed for the study, rendering the interview procedures as remarkably essential to ensure the research objective was attained.

\section{Identifying and Approaching the Research Participants}

The next step called for the identification of research participants, which was performed by accessing the registry and website of the selected Islamic charity, namely the ACNC. The organization's website allocated the participants' background details, which were gathered and reviewed accordingly. Such a selection process was especially pertinent due to their role as key informants in obtaining credible information regarding the governance for an Islamic charity. In sum, a combination of participants encompassing the board and management committees provided ample and credible information for this study. In the process of selecting the research participants, concerns regarding the right number of research participants for producing rich data arose. Regardless, the argument of having quality data was deemed more important than the number of research participants. With regard to this, Shemmings and Ellingsen (2012) advocated for a qualitative study to focus on gathering quality information from key informants rather than pushing for a large sample size.

\section{Seeking Research Participant Approval and Permission}

An email was sent to each selected research participant for their recruitment, which was attached to four important documents. They consisted of a formal invitation letter, an approval letter, a consent form, and the interview questions. The details of this study and the guidelines were well-delineated in these documents, which enabled the research participants to understand the purpose of the study and prepare accordingly for the interview. The second email detailing the meeting invitation was sent out once the researcher had received the research participant's consent. Prior to conducting the interview, the researcher had reminded the participants that the interview would be recorded for research purposes. They were then requested to sign the consent form; following this only the interview was commenced.

\section{Arranging the Interviews}

The next step required the researcher to arrange the interview accordingly to benefit all parties. Once the research participants agreed to participate in the interview, further communication with the research continued via email and phone calls to arrange the appointment. Both parties discussed the best time and place for the interview to occur. Then, the researcher sent a calendar invitation via email three days before the interview was set to happen. If there were any changes required, further communication between both parties occurred via email and phone calls to establish a rescheduled appointment.

\section{Conducting an Interview}

For this research, the researcher applied strategic reflectivity in designing the interview questions, whereby their preparation must be carefully observed. Nevertheless, there is no single appropriate format of interviewing due to various reasons, such as interview settings, interviewee perspectives, and interviewer's style of interviewing (Qu \& Dumay, 2011). 


\section{Recording the Interview}

Before conducting the interview, the researcher notified all research participants that the session would be audio-recorded. The process incorporated the use of a digital voice recorder alongside the researcher taking important notes while conducting the interview. During the session, instances of off-record discussion also occurred upon the request of the research participants.

\section{Discussions}

The overarching set of challenges faced by the researcher was shared in this paper based on the real-life experience encountered when conducting interviews in the selected Islamic NFP organizations. These challenges may be faced prior to or during the interview session with the research participants.

\section{Recruitment of Research Participants}

The researcher faced challenges in recruiting suitable and reliable research participants from the Islamic NFP organization selected. Since this study involved information gathering about their Islamic NFP practices and operation, the consent from all board members and top management must be acquired first. Therefore, a board meeting was held to gain a consensus regarding the requests of this research. Fortunately, their openness for research resulted in the opportunity for this work to elicit important information on the governance practices of Islamic NFP organizations through interview sessions. Even though the researchers obtained the official approval from the entity, potential research participants remained difficult to be reached due to their packed schedule.

\section{Research Participant Availability}

The researchers experienced a challenging task to set up an appointment that suited both the research participants and the researcher accordingly. Despite interview session time and venue being scheduled prior, a cancellation occurred due to unavoidable reasons. Since the members of Islamic charities are voluntary members, they are equally bound to their formal work duties, which sometimes hinders the interview session. In addition, some of the research participants chose venues that were unsuitable for the interview to happen, particularly due to the noisy environment.

\section{Language Barrier}

Another challenge observed in conducting the research was the language barrier encountered. The researcher faced difficulties during the interview sessions due to the different dialects used by the research participants. Majority of them are Australia-born Arabic speakers who predominantly speak English with a thick accent. Therefore, it was quite a challenge for the researcher to understand their speech, which also explained the reason behind the lengthy interview duration. The interview question required 90 minutes of the interview session to be answered sufficiently

\section{Confidentiality of The Information}

The confidentiality of information with regard to the organizational practices being upheld by the organization rendered it extremely challenging for the researcher to elicit important data. Some of the research participants were seemingly reluctant to disclose some information, as they were cautious in case of such "secret information" to result in an adverse effect on them. In addition, one of the research participants asked to off-record the conversation during their interview session. 


\section{Conclusions}

The utilization of qualitative research enabled the research questions for this research to be answered effectively. Meanwhile, the challenges faced by the researchers during the process could be overcome by several means proposed by previous studies. First, the research participant recruitment and selection for interview time and venue can be planned by establishing an interview protocol (Turner, 2010). Next, the research participants may opt for an expert to translate their conversation and context to eliminate the language barrier (Van Nes at al., 2010). As a conclusion, the findings of this paper offered great insight for future researchers regarding possible challenges and solutions in conducting an interview for Islamic NFP organization's governance research.

\section{References}

Arshad, R., Razak, H. A., \& Bakar, N. A. (2014). Assessing the self-governance and value creation in non-profit organisations. Procedia -Social and Behavioral Sciences, 145, 286-293.

Azmi, N. F., Hasan, H., \& Yusoff, M. N. H. (2018). A review of the literature of Islamic charities between 2008-2018. In International Seminar on Entrepreneurship and Business (ISEB 2018).

Chokkalingam, T. S. V, \& Ramachandran, T. (2015). The perception of donors on existing regulations and code of Governance in Singapore on charities and non-profit organizations : A conceptual study. Asian Social Science, 11(9), 89-95.

Cornforth, C. (2012). Nonprofit Governance Research. Nonprofit and Voluntary Sector Quarterly (Vol. 41).

Creswell, J. W. (2014). Research design: Qualitative, quantitative, and mixed methods approach (4th ed.). Thousand Oaks: Sage publications.

Doz, Y. L. (2011). Qualitative research for international business. Journal of International Business Studies, 42(5), 582-590.

Holloway, I., \& Biley, F. C. (2011). Being a Qualitative Researcher. Qualitative Health Research, 21(7), 968-975.

Kyngäs, H. (2020). Qualitative Research and Content Analysis. In The Application of Content Analysis in Nursing Science Research (pp. 3-11). Springer, Cham.

McNulty, T., Zattoni, A., \& Douglas, T. (2013). Developing Corporate Governance Research through Qualitative Methods: A Review of Previous Studies. Corporate Governance: An International Review, 21(2), 183-198.

Merriam, S. B. (2009). Qualitative Research A Guide to Design and Implementation Revised. San Francisco: Josseey-Bass.

Morse, J. M., \& Richards, L. (2002). Read me first for a user's guide to qualitative methods, 262.

Pamela, B., \& Jack, S. (2008). Qualitative Case Study Methodology: Study Design and Implementation for Novice Researchers. Qual Rep, 13(4), 544-559.

Patton, M. Q. (2002). Qualitative research and evaluation methods (3rd ed.). Thousand Oaks, California: Sage Publications.

Ponterotto, J. G. (2010). Qualitative research in multicultural psychology: Philosophical underpinnings, popular approaches, and ethical considerations. Cultural Diversity and Ethnic Minority Psychology, 16(4), 581-589.

Turner III, D. W. (2010). Qualitative interview design: A practical guide for novice investigators. The qualitative report, 15(3), 754-760. 
Van Nes, F., Abma, T., Jonsson, H., \& Deeg, D. (2010). Language differences in qualitative research: is meaning lost in translation? European Journal of Ageing, 7(4), 313-316. 